\section{Edycasaice

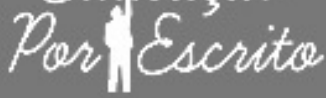

ARTIGO

\section{Editores}

Maria Inês Côrte Vitoria PUCRS, RS, Brasil

Pricila Kohls dos Santos PUCRS, RS, Brasil

\section{Equipe Editorial}

Carla Spagnolo

PUCRS, Brasil

Rosa Maria Rigo

PUCRS, Brasil

\title{
Educação Superior no Brasil: discussões e reflexões
}

\author{
Higher Education In Brazil: discussions and reflections
}

\author{
Larici Keli Rocha Moreira ${ }^{a}$ \\ Laine Rocha Moreirab \\ Marta Genú Soares ${ }^{c}$
}

\section{RESUMO}

Este artigo trata de uma revisão teórica que reflete os aspectos gerais que norteiam a educação superior no Brasil desde o processo de criação das universidades, as quais teve sua implantação legitimada pelo poder público em 1920. O estudo objetiva analisar as políticas públicas de acesso e democratização da educação superior no país. Para tanto, discute as principais políticas educacionais e o cenário atual vivido pela universidade. Debate como problemática de estudo, as questões relacionadas à concepção, funções e autonomia da universidade, que apesar de garantida em lei, tem enfrentado dificuldades para se efetivar na prática. Considera dispositivos legais que tratam da temática e pauta suas discussões baseadas em autores como Fávero (1999, 2006), Zoccoli (2009), Dourado (2008), Catani e Oliveira (2007). Conclui-se que a educação superior no Brasil tem seu reconhecimento pela legalidade da universidade, efetivação e consolidação, por meio da legislação e políticas educacionais. A expansão das universidades particulares e a isenção fiscal para investidores no setor aconteceram nos anos 80, a ação de organismos internacionais no país foi intensificada nos anos 90 e a década de 2000 é marcada por políticas de caráter transformador, porém com retrocessos provocados pela conjuntura política do Estado. Palavras-chave: Educação Superior; Universidade; Política Pública

\section{ABSTRACT}

This article is a theoretical review that treats the general aspects guiding the higher education in Brazil, since the process of creating universities, which had its implementation legitimized by the public power in 1920. The

a Professora no Instituto Federal de Educação, Ciência e Tecnologia do Pará Campus Altamira. Graduação em Licenciatura em Educação Física pela Universidade do Estado do Pará (UEPA) (2011). Especialista em Metodologia do Ensino na Educação Superior pelo Centro Universitário Internacional UNINTER

b Professora Auxiliar da UEPA. Mestre em Educação pela UEPA (2015).

c Professora da Universidade do Estado do Pará efetivada como Titular, lotada no PPGED/UEPA. Pós-Doutora pela Université de Montpellier (2015) e pela Pontifícia Universidade Católica do Rio de Janeiro (2015). Doutora em Educação pela Universidade Federal do Rio Grande do Norte (2004) e Mestre em Educação pela Universidade Metodista de Piracicaba (1998). 
study aims to analyze public policies for access and democratization of higher education in the country. For this purpose, it discusses the main educational policies and the current scenario experienced by the university. It debates the questions related to the university's conceptions, functions, and autonomy, in which besides legally guaranteed it still face difficulties to accomplish itself in practice. It considers legal devices that deal with the theme and substantiates the discussions on authors such as Fávero (1999, 2006), Zoccoli (2009), Dourado (2008), Catani and Oliveira (2007). It concludes that higher education in Brazil has its recognition by the university's legality, realization, and consolidation, through legislation and educational policies. The expansion of private universities and tax exemption for investors in this sector occurred in the 80's, the action of international organizations in the country was intensified in the 90 's, and the 2000's is marked by transforming policies, however with regressions caused by the State's political situation.

Keywords: Higher Education; University; Public Policy

\section{Introdução}

A

s mudanças na sociedade a partir da Revolução Industrial, ocorrida em meados do século XVIII na Inglaterra, mudaram o modo de viver do homem. Com a evolução das máquinas, o homem tornou-se prisioneiro dos meios de produção em massa e do capitalismo emergente, que teve como características o trabalho e o capital. Mas, foi principalmente a partir da década de 90, que o expressivo progresso tecnológico e científico influenciou a sociedade, de maneira mais específica na forma do homem se relacionar com o trabalho.

Estas inovações tecnológicas fazem com que a busca do conhecimento seja cada vez maior, uma vez que o mercado exige profissionais polivalentes, capacitados, que se adaptam as diversas situações que surgem e constantemente buscam qualificação frente às exigências do mercado. O novo perfil deste trabalhador requer autonomia, trabalho em equipe, flexibilidade, dinamicidade, dentre outras, e, mais do que em outras épocas, faz-se necessária a aquisição de habilidades por meio da mediação do conhecimento, este, alcançado pela educação.

A formação desse novo perfil de trabalhador advindo da evolução industrial e tecnológica necessita de uma pedagogia de ensino inovadora, para que o professor, por meio da sua metodologia, desenvolva a capacidade intelectual, instigue a leitura da realidade e a transformação desta pela vivência e experiência adquirida pelos alunos. A busca pela qualificação profissional acentuou-se principalmente no ensino superior, proporcionando nos últimos anos um grande crescimento no número das instituições que ofertam esta modalidade de ensino. 
Nesse contexto, emerge as questões centrais desse estudo, como problema a ser investigado: Quais os aspectos gerais que norteiam a educação superior no Brasil, desde o processo de criação das universidades e sua implantação legitimada pelo poder público? Quais as principais políticas educacionais desenvolvidas para a garantia da efetivação da universidade no passar dos anos? Qual o cenário atual da educação superior no país?

Com o objetivo de analisar as políticas públicas de acesso e democratização da educação superior no Brasil, esse estudo aborda questões relacionadas à concepção da universidade, suas funções e, principalmente, sua autonomia, que apesar de sua garantia em lei, tem enfrentado dificuldades para se efetivar na prática. Visa auxiliar com um contínuo debate, vislumbrando o aperfeiçoamento constante da qualidade da educação oferecida e a qualidade de ensino almejada.

Trata-se de um estudo de caráter exploratório, e sua construção apoia-se em uma pesquisa bibliográfica e análise documental de temas relevantes para a compreensão do tema abordado. Para Marconi e Lakatos (2003), as pesquisas do tipo documental possuem foco voltado para a busca de dados e informações, constituindo-se assim, uma coleta de dados em fontes primárias, que "podem ser feitas no momento em que o fato ou fenômeno ocorre, ou depois" (MARCONI; LAKATOS, 2003, p. 37). A pesquisa bibliográfica, por sua vez, constitui-se de consulta a fontes secundárias, com objetivo de consultar bibliografia já publicada em relação ao tema objeto de estudo, com o objetivo de "colocar o pesquisador em contato direto com tudo o que foi escrito, dito ou filmado sobre determinado assunto" (MARCONI; LAKATOS, 2003, p.39).

Dessa forma, espera-se que este trabalho possa contribuir no entendimento das principais políticas públicas de Estado desde a criação até os dias atuais da universidade brasileira.

\section{Questões e reflexões sobre a história da universidade brasileira}

Etimologicamente a palavra universidade é um vocábulo de origem latina, universitate, que significa universalidade, totalidade, conjunto, corpo, companhia, corporação, comunidade (FERREIRA, 1986).

A existência da universidade, segundo Nogueira (2004), se justifica na produção do conhecimento, na formação de cidadãos com pensamento crítico, de profissionais capazes de articular saberes e se tornarem líderes intelectuais. Todavia, por esta instituição ser historicamente determinada, não é perfeita nem inquestionável, por isso, está em constante ressignificação de seu espaço, todos que a compõem são responsáveis por sua imagem e desempenho.

A criação das instituições de educação superior no Brasil trava muitas discussões e questionamentos, porém conhecer sua realidade, criação e organização torna-se um grande desafio, principalmente para aqueles que buscam forças para empreender mudanças e transformações em seu ambiente. 
O conhecimento da universidade como um espaço de emancipação humana como se tem neste século XXI, se fez após muitas lutas e batalhas travadas em busca de sua efetivação e consolidação por uma instituição com qualidade social da educação superior.

A universidade tem seus primórdios que remontam a Idade Média, mas a institucionalização da educação superior no Brasil é recente e data de 1920. Em março de 1915, pela Reforma Carlos Maximiliano (Decreto n. ${ }^{\circ}$ 11.530/1915), o ensino secundário e superior passa por uma reorganização e o governo tem mais controle sobre os mesmos (ZOCCOLI, 2009, p. 59 e 60).

Para Fávero (1999, p. 02) com a criação da Universidade do Rio de Janeiro, por meio do Decreto n. ${ }^{0} 14.343$ de 7 de setembro de 1920, o Governo Federal adota outras medidas institucionais que influenciaram diretamente no controle da autonomia da universidade. Para o autor:

O controle sobre as universidades federais, a partir daí, torna-se cada vez mais explícito. Com a reforma do Ensino Superior promovida pelo Ministro Francisco Campos, em 1931, um ponto bastante acentuado é a concessão da autonomia relativa à universidade, como uma preparação para a autonomia plena. Apesar da justificativa de não ser possível, naquele momento, conceder-lhes "autonomia plena", tanto no plano didático, como no administrativo, a questão ficou, a rigor, em aberto.

O autor supracitado afirma que em decorrência da instituição da primeira universidade no Brasil, um debate em torno do problema universitário foi reavivado, e ainda, expressa a importância deste à atuação da Associação Brasileira de Educação (ABE) e da Academia Brasileira de Ciências (ABC). Dentre as discussões em pauta têm-se questões relacionadas à concepção de universidade no país, suas funções, sua autonomia e seu modelo (FÁVERO, 2006 p. 22).

Outros dois decretos estruturaram e consolidaram a educação superior no país, o Decreto no 19.851/1931, referente ao Estatuto das Universidades Brasileiras, e o decreto no 19.852/1931 que dispõe sobre a reorganização da Universidade do Rio de Janeiro. Vale destacar, a criação do Conselho Nacional de Educação, pelo Decreto no 19.850/1931. Estes foram elaborados e implementados pelo primeiro titular, Francisco Campos, do Ministério da Educação e Saúde Pública, criado em 1930 pelo Governo Provisório. Ressalta-se ainda neste período, a criação da Universidade de São Paulo (USP), em 1934, e da Universidade do Distrito Federal (UDF), em 1935, e, ainda, em 1938, da União Nacional dos Estudantes (UNE), movimento estudantil que propunha uma reforma universitária, por meio de debates, que combatesse o caráter arcaico e elitista das instituições universitárias (ZOCCOLI, 2009). 
As décadas de 50 e 60 foram marcadas pela criação de novas universidades federais, e em 1961 foi aprovada a Lei de Diretrizes e Bases da Educação Nacional (Lei no 4.024/61), que estabelecia a autonomia das universidades (DOURADO, 2008). Sobre análise de Fávero (1999, p. 03) a mesma lei restringia esta autonomia, dando poder ao Conselho Federal de Educação, de "aprovar estatutos das universidades e promover sindicâncias por meio de comissões especiais em quaisquer estabelecimentos de ensino superior, tendo em vista o fiel cumprimento desta lei" e ainda "se tal dispositivo não teve implicações mais significativas até o golpe militar de 1964; a partir daí, esse dispositivo foi aplicado, em alguns casos de maneira bastante discricionária".

Segundo Zoccoli (2009), no ano de 1961 foi instituída, por meio da Lei no 3.998, de 15 de dezembro de 1961, a Universidade de Brasília (UnB). Neste mesmo ano, o então ministro da Educação e Saúde, Clemente Mariani, juntamente com uma comissão composta por membros de diversas tendências e após várias discussões, promulgam a Lei de Diretrizes e Bases da Educação Nacional (LDB), Lei no 4.024/1961. Esta propunha liberdade de ensino, igualdade na destinação de recursos para a educação e atribuições ao Ministério da Educação e do Desporto no que concerne a formulação e avaliação das políticas nacionais de educação. Outro aspecto relevante nesta lei foi a criação do Conselho Federal de Educação, que seria instalado no ano seguinte.

A mesma autora aponta que as décadas de 60 e 70 foram marcadas pela preocupação do Estado com a educação, vendo esta como meio capaz de preparar tecnicamente trabalhadores para indústrias. Mudanças foram empreendidas na área universitária, "com o objetivo da racionalização dos serviços e da modernização do aparato estatal, visto o crescimento das universidades” (ZOCCOLI, 2009, p. 76). Neste período a educação passa a perder qualidade, pois faltava planejamento, fiscalização nos instrumentos de avaliação e acompanhamento por parte do governo, formavase apenas para suprir demandas de mercado, educação tecnicista, vista como um instrumento para contribuir com a consolidação do processo de desenvolvimento (ZOCCOLI, 2009).

No período da Ditadura Militar, os Atos Institucionais (AI), principalmente o AI no 5, de 13 de dezembro de 1968, limitava ainda mais a autonomia universitária, além disso, o regime ainda perseguia professores, estudantes e funcionários (FÁVERO, 1999).

Com o objetivo de conservar o princípio de autoridade dentro das instituições de ensino e conter os problemas educacionais existentes nas universidades brasileiras, o governo cria o Decreto $\mathrm{n}^{\mathrm{o}} 62.024$, de 29 de dezembro de 1967. Este designava uma comissão especial, presidida pelo General Meira Mattos, com a finalidade de mapear as reinvindicações estudantis, planejar, propor, coordenar e executar diretrizes governamentais no setor, a fim de "instaurar no meio universitário um recurso de intimidação e de repressão" (FÁVERO, 2006, p. 31-32).

O relatório realizado por esta comissão leva a aprovação, em caráter de urgência, da Lei no 5.540, de 28 de dezembro de 1968, a chamada Reforma Universitária, que teve suas medidas propostas com a finalidade de melhorar 
a operacionalização da universidade, dentre elas, "o sistema departamental, o vestibular unificado, o ciclo básico, o sistema de créditos e a matrícula por disciplina, bem como a carreira do magistério e a pós-graduação" (FÁVERO, 2006, p. 34).

Para Zoccoli (2009, p. 83) a Reforma Universitária entre outras ações:

Extinguiu as cátedras, introduziu para os professores o regime de trabalho de tempo integral e dedicação exclusiva, criou a estrutura de departamentos, o vestibular eliminatório, instituiu os créditos por disciplina e implantou a indissociabilidade entre ensino, pesquisa e extensão.

De acordo com Saviani (1999), nesta época foi aprovada a Lei no 5.692 de 11 de agosto de 1971, que elevou para oito anos a obrigatoriedade do ensino fundamental, ressaltaram o caráter quantitativo do ensino, diminuiu os recursos repassados a educação e fortaleceu o ensino profissionalizante.

Com o fim da ditadura militar, foi retomada a democracia no país com moldes capitalistas, resultando em inúmeras reformas nas políticas educacionais. Neste sentido, Dias Sobrinho (2005), aponta que as décadas de 1970 e 1980 são marcadas pela expansão das universidades particulares e a isenção fiscal para investidores no setor, isto porque o governo passou a descentralizar as responsabilidades e a centralizar o poder.

Em vigência até hoje, a Constituição Federal (CF) de 1988, trouxe em seu bojo uma esperança em reordenar o sistema educacional do Brasil e consolidou, após muitos embates, a autonomia universitária. Contudo, o poder centralizador do Estado fragilizava as articulações para o progresso da educação.

\section{A Educação Superior e a Constituição Federal de 1988}

A Constituição Federal (CF) de 1988 cita a educação superior especificamente nos artigos 207, 208, 213 e 218. O artigo 207 representa uma luta histórica travado pelos professores e comunidade científica em geral a favor da liberdade acadêmica e da autogestão. Este assegura que "as universidades gozam de autonomia didático-científica, administrativa e de gestão financeira e patrimonial, e obedecerão ao princípio da indissociabilidade entre ensino, pesquisa e extensão" (BRASIL, 1988). Para Catani e Oliveira (2007), a pesquisa, o ensino e a extensão não poderão ser separados e constituem elementos essenciais na organização e na produção científica dentro da universidade, a fim de consolidar o desenvolvimento das atividades acadêmicas.

Ainda sobre a educação superior, o artigo 208, inciso V, estabelece como dever do Estado com a educação à garantia do "acesso aos níveis mais elevados do ensino, da pesquisa e da criação artística, segundo a capacidade de 
cada um" (BRASIL, 1988). Há autores que ao discutirem este inciso, chamam atenção para a segunda parte do texto, ao refletirem sobre a maneira em que este acesso se efetiva. As discussões que envolvem este inciso pautam-se na concepção de que a educação superior não poderá ser atingida por todos, tendo a noção desta como educação elitista, que será alcançada pelos privilegiados.

Ao reportar sobre a destinação dos recursos públicos a educação, a Constituição Federal de 1988, estabelece em seu artigo 213, § 2o , que "as atividades universitárias de pesquisa e extensão poderão receber apoio financeiro do Poder Público" (BRASIL, 1988). Para Catani e Oliveira (2007), este parágrafo coloca a educação superior como uma possibilidade e afirmam que há nele uma ausência de garantia efetiva do apoio financeiro ao ensino superior.

Além destes artigos é valido destacar o artigo 212, que faz referência ao financiamento da educação e estabelece um limite mínimo de investimento a ser realizado pela união, com percentual de $18 \%$, e pelos Estados, Distrito Federal e Municípios, com 25\%, ambos recursos "da receita resultante de impostos, compreendida a proveniente de transferências, na manutenção e desenvolvimento do ensino" (BRASIL, 1988).

Sobre os aspectos gerais da educação superior, Catani e Oliveira (2007, p. 78) corroboram que a Constituição Federal de 1988 que

Instituiu princípios e mecanismos importantes para a organização do trabalho nas IFES. Dentre eles, garantiu-se a investidura em cargo ou emprego público mediante a aprovação prévia em concurso público de provas ou de provas e títulos (artigo 37, II), aboliram-se as restrições legais que impediam aos servidores públicos de se filiarem a sindicatos (artigo 37, VI) e instituiu-se regime jurídico único e plano de carreira homogêneo para os servidores (docentes e funcionários técnico-administrativos) de todas as IFES do país (art. 24 e 39).

Porém, com o processo da globalização e do neoliberalismo emergente no Brasil, significativas mudanças, entre elas a mercantilização de serviços e da própria educação com a oferta de centenas de cursos superiores de baixo custo e de baixa qualidade nas condições de oferta, que aconteceram no processo produtivo e nas relações sociais e de trabalho impulsionadas pela "reestruturação capitalista". Essas mudanças implicaram diretamente numa "maior concentração de riquezas, incremento da corrupção, privatização da esfera pública e, consequentemente, o alargamento das injustiças sociais e a diversificação e intensificação dos processos de exclusão social" (DOURADO, 2002, p. 236).

Com a eleição de Fernando Collor e as privatizações realizadas no período houve um descrédito da educação em todos os níveis, diminuindo os investimentos por parte do governo federal. Notadamente neste período, as prerrogativas legais estabelecidas na CF não se concretizavam na prática. Este descrédito dado à educação levou a 
uma crise, principalmente no ensino superior, que resultou em: "deterioração do salário dos professores, péssimas condições de trabalho, resultando ainda, em inúmeras greves e mobilizações” (ZOCCOLI, 2009 p. 87).

\section{Anos 90: a Educação Superior e a LDB}

O modo de produção e de organização da sociedade e as demandas econômicas do capitalismo incidiram diretamente no âmbito educacional, implicando em propostas para o setor, principalmente no que diz respeito à gestão educacional. Neste período, foi intensificada a ação de organismos internacionais no Brasil, como o Banco Mundial, o Banco Interamericano de Desenvolvimento (BID) e agências da Organização das Nações Unidas (ONU). Ao fazer uma análise sobre a atuação do Banco Mundial, Dourado (2002, p. 238) assinala que este organismo:

Exerce no campo educacional na América Latina e, particularmente, no Brasil ao difundir, entre outras medidas, em seus documentos uma nova orientação para a articulação entre educação e produção do conhecimento, por meio do binômio privatização e mercantilização da educação.

Cunha (1997), ao fazer referência ao governo de Fernando Henrique Cardoso (1995-2003), explicita que durante este período o campo educacional passou por uma intensa reforma. Ainda neste sentido, Dourado (2008) corrobora que as mudanças empreendidas por esta reforma geraram importantes alterações na forma de gestão de políticas públicas por parte do Estado, o que resultou na aprovação da Lei de Diretrizes e Bases da Educação Nacional (Lei no 9.394/96), a primeira lei complementar estabelecida para a área da educação, pós CF de 1988.

Chamada por Cunha (1996) de uma lei "minimalista", a nova LDB, aprovada após intensa turbulência de sua tramitação no Senado, representa para alguns estudiosos uma grande frustação e para outros um complemento às garantias evidenciadas na CF de 1988 sobre a educação. Esse dispositivo legal, segundo Dourado (2002, p. 242) foi precedida pela edição de leis, portarias e decretos que a nortearam, destacando-se:

A lei que determinou a mudança radical na escolha de dirigentes das universidades federais (Lei no 9.192/95), alterando a composição do colégio eleitoral e permitindo recondução de reitores e diretores aos respectivos cargos, a ser ocupados por docentes adjuntos ou titulares; a Lei no 9.131/95, que regulamentou o Conselho Nacional de Educação e instituiu avaliações periódicas nas instituições e nos cursos superiores, resultando, desde a edição da Portaria no 249/96 do MEC, nos exames nacionais de cursos (ENC-Provão); o Decreto no 2.026/96, definindo os procedimentos para avaliação das instituições de ensino superior e dos cursos.

A LDB de 1996 apresenta um capítulo dedicado à educação superior, são dispostos nos artigos 43 a 57 e serão discutidos logo a seguir alguns artigos que representam destaques nesta lei. 
Após estabelecer as finalidades da educação superior (artigo 43), a LDB prevê que esta modalidade de ensino pode ser ministrada em instituições de ensino públicas ou privadas (artigo 45), desde que estejam devidamente credenciadas com autorização e o reconhecimento de seus cursos (artigo 46). Estas poderão ofertar cursos sequenciais, cursos de graduação, cursos de pós-graduação e cursos de extensão (artigo 44). Os cursos passarão por processo regular de avaliação, e se forem constatadas deficiências, haverá reavaliação, se persistirem poderão resultar em desativação, intervenção na Instituição de Ensino Superior (IES) ou até mesmo seu descredenciamento (artigo 46, § 1ํํ)1.

No artigo 47, a LDB estabelece que o ano escolar tenha, no mínimo, 200 dias de trabalho efetivo, descontados os dias reservados aos exames finais. Os diplomas reconhecidos terão validade nacional e o reconhecimento dos diplomas expedidos por universidades estrangeiras serão registrados em universidades públicas (artigo 48). Já os artigos 49 a 51 fazem menção às formas de acesso ao ensino superior e os artigos seguintes referem-se às universidades.

A universidade é definida no artigo 52, como uma instituição pluridisciplinar, com as seguintes características: possuir pelo menos $1 / 3$ de seu corpo docente com titulação de mestrado e doutorado e também, 1/3 do corpo docente em regime de tempo integral. Já o artigo 53 confere autonomia às universidades nas seguintes atribuições:

I - Criar, organizar e extinguir, em sua sede, cursos e programas de educação superior previstos nesta Lei, obedecendo às normas gerais da União e, quando for o caso, do respectivo sistema de ensino;

II - Fixar os currículos dos seus cursos e programas, observadas as diretrizes gerais pertinentes;

III - estabelecer planos, programas e projetos de pesquisa científica, produção artística e atividades de extensão;

IV - Fixar o número de vagas de acordo com a capacidade institucional e as exigências do seu meio;

$\mathrm{V}$ - Elaborar e reformar os seus estatutos e regimentos em consonância com as normas gerais atinentes;

VI - Conferir graus, diplomas e outros títulos;

VII - Firmar contratos, acordos e convênios;

VIII - Aprovar e executar planos, programas e projetos de investimentos referentes a obras, serviços e aquisições em geral, bem como administrar rendimentos conforme dispositivos institucionais;

IX - Administrar os rendimentos e deles dispor na forma prevista no ato de constituição, nas leis e nos respectivos estatutos;

$\mathrm{X}$ - Receber subvenções, doações, heranças, legados e cooperação financeira resultante de convênios com entidades públicas e privadas.

\footnotetext{
1 Este processo regular de avaliação dos cursos e credenciamento das IES foi estabelecido na Lei no 10.861, de 14 de abril de 2004 , que instituiu o Sistema Nacional de Avaliação da Educação Superior (SINAES) com o objetivo de "assegurar processo nacional de avaliação das instituições de educação superior, dos cursos de graduação e do desempenho acadêmico de seus estudantes” (artigo 1ํ).
} 
Vale ressaltar, que essas decisões devem ser tomadas pelos órgãos colegiados das instituições, inclusive ainda aquelas relativas à contratação e dispensa de professores e a constituição de planos de carreira.

Ao reportarem sobre o artigo 54 da LDB, que assegura às universidades oficiais gozarem um "estatuto jurídico especial" (BRASIL, 1996), Catani e Oliveira (2007), explicitam que este, contraria a Constituição Federal de 1988, em seu artigo 39, que estabelece um Regime Jurídico Único. Todavia, o artigo 55 da LDB nos aponta que é obrigação da União assegurar, por meio do seu Orçamento Geral, "recursos suficientes para a manutenção e desenvolvimento das instituições de educação superior por ela mantidas" (BRASIL, 1988).

O artigo 56 da LDB faz menção à gestão democrática, assegurando a existência de órgãos colegiados deliberativos, que contenham a participação dos vários segmentos da comunidade. O parágrafo único deste artigo estabelece que "os docentes ocuparão setenta por cento dos assentos em cada órgão colegiado e comissão, inclusive nos que tratarem da elaboração e modificações estatutárias e regimentais, bem como da escolha de dirigentes". Por último, o artigo 57 obriga os docentes a ministrarem, nas instituições públicas de educação superior, no mínimo oito horas semanais de aula (BRASIL, 1996).

Magno (2008) ao fazer uma análise sobre a LDB considera que esta sugere uma grande reforma universitária que gira em torno da avaliação e da autonomia. Explicita ainda que a autonomia, neste caso, associa-se a ideia de flexibilização, quando o Estado passa as instituições uma gama de atribuições, ficando este desobrigado a financiar esta modalidade de ensino.

Ainda sobre a LDB, Raniere (2000, p. 142) aponta que:

[...] a regulamentação de tantos atributos, definindo formas de atuação e procedimentos, vem sendo feita por decretos, portarias e instruções baixadas pelo Poder Executivo Federal, por meio do Ministério da Educação. O problema dessa estratégia está na excessiva concentração de poderes no âmbito do poder público federal, com perigoso potencial para a organização federativa [...].

Corroborando esta análise sobre a LDB, Oliveira e Adrião (2007, p. 83) assinalam que essa lei:

[...] promoveu completa reestruturação da educação superior no país, em um processo que restringiu (e metamorfoseou) a atuação da esfera pública e ampliou a ação do setor privado, alterando de maneira significativa a identidade das IFES, procurando tornar a educação um bem ou um "produto", que os "clientes" adquirem no mercado universitário. 
Cabe destacar, que houve neste período a promulgação de outros instrumentos legais (leis, decretos, pareceres, resoluções, portarias) que explicitam a formulação geral da estrutura e da política de educação superior no país, dentre estes cabe destacar os decretos no 2.207/1997, que estabeleceu distinções entre Instituições de Ensino Superior (IES) públicas e privadas, e no 3.860/2001, que revogou o decreto anterior, reordenando as competências do Ministério da Educação (MEC), do Conselho Nacional de Educação (CNE) e do Instituto Nacional de Estudos e pesquisa Educacionais (INEP).

No entanto, os objetivos da educação nacional tinham estreita ligação com a conjuntura do mercado de trabalho exigida nesta época, momento em que houve um grande aumento na procura pelo ensino superior, sendo as políticas públicas voltadas para suprir as demandas dos processos produtivos, tratando a educação como mercadoria (ZOCCOLI, 2009 p. 94).

\section{Ensino Superior no Brasil e a ordem legal em pauta}

As políticas educacionais para a educação superior a partir do governo do presidente Luiz Inácio Lula da Silva (2003-2010), foram esperadas com grande expectativa de mudança, visto que esta foi uma pauta tratada no Plano de Governo apresentado pelo candidato eleito, que dentre outras medidas sinalizava uma alteração no campo das universidades públicas.

Assim, as reformas implementadas na educação superior no período do governo Lula aconteceram por meio de dispositivos legais que alteraram a dinâmica acadêmica e de gestão das IES, principalmente as públicas. Efetivaram-se, na expansão da oferta da educação superior, com a criação de 14 Universidades Federais, 10 voltadas para a interiorização do ensino superior público e 4 para promover a integração regional e internacional (ESTADAO, 2011), na criação de novos cursos, na expansão da rede federal, por meio do Programa de Apoio a Planos de Reestruturação e Expansão das Universidades Federais (REUNI), nos processos de avaliação do ensino superior, por meio do Sistema Nacional de Avaliação da Educação Superior (Sinaes), no Fundo de Financiamento Estudantil (Fies), no Programa Ciência sem Fronteiras, no Programa Universidade para Todos (Prouni), no Programa de Bolsa Institucional de Iniciação à Docência (PIBID), no Plano Nacional de Assistência Estudantil (Pnaes) e no Sistema Universidade Aberta do Brasil (UAB).

O Censo da Educação Superior, realizado em 2010 pelo Instituto de Estudos e Pesquisas Educacionais Anísio Teixeira (INEP), apresentou dados da realidade da educação superior no Brasil no período. Considerando-se a categoria administrativa e organização acadêmica, o documento revelou que o número de IES no Brasil passou de 1.391, em 2001, para 2.378, em 2010, sendo que as públicas passaram de $183 \mathrm{em} \mathrm{2001,} \mathrm{para} 278$ em 2010 e as 
privadas passaram de $1.208 \mathrm{em}$ 2001, para $2.100 \mathrm{em}$ 2010. Nota-se que houve um crescimento maior de instituições privadas, que em 2010 representava $88,3 \%$ do total de instituições superiores no país. Do percentual de IES públicas divulgados pelo INEP, 4,5\% são estaduais, 4,2\% são federais e 3,0\% são municipais (INEP, 2010 p. 30).

Em relação ao acesso a educação superior, os dados apontaram uma maior busca pela qualificação profissional no período pesquisado, evidenciados na quantidade de matrículas nos cursos de graduação, sendo 1.643.298 nas IES públicas e 4.736.001 nas IES privadas, totalizando 6.379.299 matrículas no ano de 2010, o que apresenta uma significativa expansão do acesso a este nível de ensino no período pesquisado (INEP, 2010, p. 38 e 39 ).

Quanto à organização acadêmica das instituições de educação superior, os números assinalaram que dentre as 2.378 instituições em $2010,85,2 \%$ são faculdades, $8,0 \%$ são universidades, $5,3 \%$ são centros universitários e $1,6 \%$ são Institutos Federais de Educação, Ciência e Tecnologia (IF) e Centros Federais de Educação Tecnológica (Cefet) ${ }^{2}$ (INEP, 2010, p. 32 e 33).

Esses dados nos permitem entender o panorama da educação superior no país encontrado pela Presidente Dilma Rousseff em $1^{\circ}$ de janeiro de 2011 quando tomou posse. Vale destacar, que além de dar sequência as ações implementadas no governo anterior, o primeiro governo da presidente (2011-2014), deu ênfase na ampliação da oferta de vagas em universidades e institutos federais, como exemplo tem-se a publicação em agosto de 2012, da Lei no 12.711 , que criou cotas para a rede pública nas universidades federais, instituiu a reserva de $50 \%$ das vagas ofertadas em instituições federais de educação superior para estudantes provenientes de escolas públicas, e estabeleceu um prazo de quatro anos para que todas as instituições cumprissem o disposto na legislação.

Sob o olhar de Colares e Sindeaux (2015), o aumento do número de matrículas proposto pela política de democratização do acesso à universidade pública não caminhou em conjunto com os investimentos em infraestrutura necessária para que os pilares da universidade - ensino, pesquisa e extensão - se efetivassem com qualidade.

As medidas implementadas pela expansão dada pelo REUNI, considerada desordenada pela classe de servidores que compõem o ensino federal, geraram uma grande insatisfação que, durante os anos iniciais do primeiro mandato do governo da presidente Dilma, entraram em greve duas vezes. Dentre as reivindicações estavam o reajuste salarial, a reestruturação das carreiras, melhores condições de trabalho, a luta contra mercantilização do ensino promovida nos últimos anos com a expansão do ensino superior privado e o sucateamento das universidades federais em detrimento

2 A Lei no 11.892, de 29 de dezembro de 2008, instituiu a Rede Federal de Educação Profissional, Científica e Tecnológica, vinculada ao MEC e criou os Institutos Federais de Educação, Ciência e Tecnologia (IFs), autarquias com autonomia administrativa, financeira, didático pedagógica, patrimonial e disciplinar, com a finalidade de oferta, dentre outros níveis e modalidades, de cursos de educação superior (tecnólogos, licenciaturas, bacharelado e engenharia), cursos de pós-graduação lato e stricto sensu, além da realização de atividades de pesquisa e extensão (BRASIL, 2008).

Educação Por Escrito, Porto Alegre, v. 9, n. 1, p. 134-150, jan.-jun. 2018 
da expansão dos investimentos do Governo Federal no PROUNI. No ano de 2012, a paralisação durou mais de 120 dias e atingiu 59 universidades federais e 40 institutos federais de educação, o que correspondeu a mais de $90 \%$ das instituições federais de educação superior (COLARES; SINDEAUX, 2015).

A insatisfação dos servidores da educação aumentou ainda mais com o ajuste fiscal presente no início do segundo mandato do governo da presidente Dilma Rousseff (2015-2018). Em 2015, os cortes no orçamento afetaram os recursos destinados à educação e atingiram diretamente o funcionamento das universidades federais. O pagamento de bolsas de permanência estudantil, bolsa de pesquisa e assistência e o salário de trabalhadores terceirizados foram atrasados e o grande alvo de críticas do governo Dilma surgiu com a apresentação do novo lema do seu governo, "Pátria Educadora", o qual reduziu os investimentos para a educação ao invés de ampliá-los (GOMES, 2016).

A insatisfação popular que iniciou em 2013 e posteriormente a insatisfação geral com os políticos, as constantes denúncias de corrupção e a deflagração da Operação Lava Jato, em 2014 pela Polícia Federal, que atingiu importantes nomes do governo, culminou no pedido de impeachment e sua aprovação pela Câmara dos Deputados e Senado Federal, em maio e agosto de 2016 respectivamente, quando assumiu a presidência da república o vice Michel Temer.

A ameaça às universidades federais se intensificou no governo Temer e não se dá apenas pela relação de cortes de recursos que continuam como também uma grande tendência à privatização desta instituição e de ataques aos direitos de seus trabalhadores. Segundo Gomes (2016), a privatização da parte principal da previdência de seus servidores, privatização dos hospitais universitários, etc., tem contribuído para a deterioração da educação pública e das universidades federais.

Com o quadro da precarização das condições de trabalho e a degradação da qualidade do ensino ofertado, no ano de 2016 aconteceu a mais longa greve docente da história das instituições federais de ensino superior, chegando a 130 dias de paralisação, o que mostra oposição às políticas em andamento.

Os servidores públicos federais têm lutado contra as medidas que o governo Temer vem adotando contra os direitos dos trabalhadores, que estão dentre as medidas o adiamento de reajuste da carreira docente federal, prevista para agosto de 2017, o aumento da contribuição previdenciária de $11 \%$ para $14 \%$, a modificação das carreiras do Executivo Federal e a oficialização da Medida Provisória 792/2017, que instituiu o Programa de Demissão Voluntária. A conjuntura nacional é de crise financeira que está afetando diretamente o funcionamento das universidades e institutos federais, com o corte do orçamento muitas instituições públicas de educação correm o risco de fechar as portas (SINASEFE, 2017).

Em meio ao cenário de lutas pela manutenção da educação pública, foi publicado em agosto de 2017 o resultado do Censo da Educação Superior 2016, que aponta o minúsculo crescimento de 0,2\% na quantidade de matrículas 
nas universidades públicas quando comparado com o ano de 2015, e que as 197 universidades públicas equivalem a $8,2 \%$ do total de IES no Brasil. Do total de ingresso na educação superior, o censo apontou que quase 3 milhões de alunos ingressaram nos cursos de graduação e destes apenas $17,7 \%$ ingressaram em instituições públicas que ofertam a modalidade. $\mathrm{O}$ crescimento de ingressos foi maior na educação à distância, $20 \%$, quando comparado à educação presencial, 3,7\%, sendo que houve um decréscimo de 3,7\% quando comparado ao ano de 2015 (INEP, 2017).

Estes dados confirmam a precarização da educação superior pública no país. As universidades federais têm enfrentado grandes desafios no aspecto relacionado aos investimentos por parte do poder público, que não acompanhou a expansão dos últimos anos. A universidade precisa ser entendida como um espaço de construção coletiva e vista como um patrimônio da sociedade e um espaço de formação ampla, que contribui para o desenvolvimento de cidadãos críticos, reflexivos e autênticos e necessita de políticas públicas que garantam a permanência e o êxito dos sujeitos envolvidos no processo formativo.

Destarte, a universidade na atualidade é chamada a ser lugar de formação de um cidadão protagonista, autêntico, crítico e reflexivo sobre a realidade em que vive. Conforme Fávero (2006, p. 19), a universidade é um espaço principal que se constitui num palco de discussões sobre a sociedade, "deve ser um espaço em que se desenvolve um pensamento teórico-crítico de ideias, opiniões, posicionamentos, como também a condução de propostas e alternativas para solução dos problemas" (FÁVERO, 2006, p. 19).

\section{Considerações finais}

Este estudo possibilitou o conhecimento acerca da trajetória histórica da educação superior no Brasil, do reconhecimento legal da universidade, sua efetivação e consolidação, uma análise e debate sobre as principais legislações, políticas educacionais e o cenário atual vivido pelas universidades brasileiras.

O estudo apontou que a primeira universidade reconhecida legalmente no Brasil surgiu no ano de 1920 no Rio de Janeiro, e desde então foram debatidas questões relacionadas à sua concepção, suas funções, sua autonomia e seu modelo. Observou-se que a autonomia universitária apareceu nos textos de dispositivos legais desde a promulgação da primeira Lei de Diretrizes e Bases, em 1961, porém esta autonomia remetia ao próprio governo, único que poderia aprovar estatutos e promover sindicâncias. Já nas décadas de 60 e 70 a educação superior era vista tão somente como um meio capaz de preparar tecnicamente trabalhadores para indústrias.

A expansão das universidades particulares e a isenção fiscal para investidores no setor aconteceram com mais força nos anos 80, ano em que foi promulgada a Constituição Federal de 1988 ainda em vigor. A ação de organismos 
internacionais no Brasil foi intensificada nos anos 90, o que resultou em uma intensa reforma no campo educacional, com a aprovação da nova LDB de 1996, que possui um capítulo dedicado à educação superior.

A partir dos anos 2000 mudanças significativas aconteceram nos aspectos relacionados a democratização do acesso à universidade no país, com políticas de caráter transformador, que ampliaram a oferta de vagas. Mesmo com os avanços nas políticas, na atualidade a universidade vive momentos de retrocessos provocados pela conjuntura política do Estado, principalmente no que diz respeito a manutenção da qualidade da educação pública.

Considerando que a universidade, pela sua natureza e finalidade, é palco de discussões sobre a realidade vivida pela sociedade, é um lugar que produz conhecimento, organiza e articula saberes, forma cidadãos, profissionais intelectuais críticos e reflexivos, capazes de transformar a realidade em que vive, porém precisa ser entendida como uma política pública que requer atenção e investimento do Estado. Para que se torne um ambiente de transformação humana e social, faz-se necessário uma maior participação ativa e efetiva da sociedade, bem como ajustes no que concerne à organização, gestão e financiamento dessa modalidade de ensino, o que converge para a democratização do acesso a educação superior.

\section{Referencias}

BRASIL. Constituição da República Federativa do Brasil. Brasília: Senado Federal, 1988.

BRASIL. Lei de Diretrizes e Bases da Educação Nacional. Lei no 9.394, de 20 de dezembro de 1996. Diário Oficial da União, Brasília, 23 dez. 1996, p. 27894.

CATANI, Afrânio; OLIVEIRA, João. A Educação Superior. In: OLIVEIRA, R. P.; ADRIÃO, T. Organização do ensino no Brasil: níveis e modalidades na Constituição Federal e na LDB. São Paulo: Xamã, 2007.

COLARES, André Felipe Vieira; SINDEAUX, Roney Versiani. Greve nas universidades federais em 2012: um movimento na academia e sua repercussão na sociedade. In: Textos \& Debates, Boa Vista, n.24, p.61-77, 2015. Disponível em: <https://revista.ufrr.br/ textosedebates/article/view/1820/1486>. Acesso em: 08 maio 2018.

CUNHA, Luiz Antônio. Nova reforma do ensino superior: a lógica reconstruída. Cad. Pesq. n. 101, p. 20-40, jul. 1997. Disponível em: <http://www.fcc.org.br/pesquisa/publicacoes/cp/arquivos/254.pdf>. Acesso em: 12 ago. 2017.

CUNHA, Luiz Antônio. Crise e reforma do sistema universitário no Brasil: até onde irá a autonomia universitária?. Educação e Sociedade, Campinas, n. 55, ago. 1996.

DIAS SOBRINHO, J. Dilemas da educação superior no mundo globalizado: sociedade do conhecimento ou economia do conhecimento. São Paulo: Casa do Psicólogo, 2005. 
DOURADO, Luiz Fernandes. Políticas e gestão da Educação Superior: múltiplas regulações e Reforma Universitária no Brasil. In: VII Seminário da RedEstrado. Buenos Aires, 2008. Disponível em: <http://flacso.redelivre.org.br/files/2013/03/1096.pdf>. Acesso em: 28 jul. 2017.

DOURADO, Luiz Fernandes. Reforma do Estado e as políticas para a educação superior no Brasil nos anos 90 . In: Educação e Sociedade, v. 23, n. 80. Campinas, 2002, p. 234-252. Disponível em: <http://www.scielo.br/pdf/es/v23n80/12931.pdf>. Acesso em: 12 jul. 2017.

ESTADAO, O Estado de São Paulo. Mais universidades federais. São Paulo, 22 ago. 2011. Disponível em: <http://opiniao.estadao. com.br/noticias/geral,mais-universidades-federais-imp-,761771>. Acesso em: 19 out. 2017.

FÁVERO, Maria de Lourdes de A. Autonomia Universitária no Brasil: uma utopia. In. EPAA, v. 7, n. 24, 1999. Disponível em: <http:// epaa.asu.edu/ojs/article/download/559/682>. Acesso em: 19 out. 2017.

FÁVERO, Maria de Lourdes de A. A Universidade no Brasil: das origens à Reforma Universitária de 1968. In: Educar, Curitiba, n. 28, p. 17-36, 2006. Disponível em: <http://www.scielo.br/pdf/er/n28/a03n28.pdf>. Acesso em: 26 jul. 2017.

FERrEIRA, Aurélio Buarque de Holanda. Novo Dicionário da Língua Portuguesa. 2. ed. Rio de Janeiro: Nova Fronteira, 1986.

GOMES, José Menezes. 21 anos de Plano Real, sistema da dívida e ajuste fiscal. Universidade e Sociedade, Brasília, v. 26, n. 57, jan. 2016.

INEP, Instituto Nacional de Estudos e Pesquisas Educacionais Anísio Teixeira. Censo da educação superior: 2010 - resumo técnico. - Brasília: Instituto Nacional de Estudos e Pesquisas Educacionais Anísio Teixeira, 2012. Disponível em: <http://download.inep.gov. br/download/censo/2010/divulgacao_censo2010_201210.pdf>. Acesso em: 22 ago. 2017.

INEP, Instituto Nacional de Estudos e Pesquisas Educacionais Anísio Teixeira. MEC e Inep divulgam dados do Censo da Educação Superior 2016. 2017. Disponível em: < http://portal.inep.gov.br/artigo/-/asset_publisher/B4AQV9zFY7Bv/content/id/854595>. Acesso em: 22 set. 2017.

MAGNO, Michelle Feitosa. Estado, direito e políticas públicas: um estudo sobre a incidência normativa na Educação Superior a partir da Constituição Federal de 1988. Dissertação (Mestrado em Educação) - Programa de Pós-Graduação em Educação, Instituto de Ciências da Educação, Universidade Federal do Pará, Belém, 2008. Disponível em: <http://www.repositorio.ufpa.br/jspui/handle/2011/1869>. Acesso em: 05 jul. 2017.

NOGUEIRA, Marco Aurélio. Universidade, conhecimento e opinião. 2004. Disponível em <http://www.acessa.com/gramsci/?id=3 8\&page= visualizar $>$. Acesso em: 01 ago. 2017.

OLIVEIRA, Romualdo Portela; ADRIÃO, Theresa. Gestão, financiamento e direito à educação: análise da Constituição Federal e da LBD. São Paulo: Xamã, 2007.

RANIERE, Nina Beatriz Stocco. Educação Superior, Direito e Estado na Lei de Diretrizes e Bases (Lei no 9.394/96). São Paulo: EDUSP: FAPESP, 2000. 
SAVIANI, Dermeval. Política e educação no Brasil: o papel do congresso nacional na legislação do ensino. Campinas: Autores Associados, 1999.

SINASEFE, Sindicato Nacional dos Servidores Federais da Educação Básica, Profissional e Tecnológica. Não é ajuste fiscal! É a destruição do serviço público que vai afetar a vida de todos os brasileiros. Disponível em: <http:/sinasefepa.org/index.php/comunicacao/noticias/ 93-ultimas-noticias/2032-nao-e-ajuste- fiscal-e-a-destruicao-do-servico-publico-que-vai-afetar-a-vida-de-todos-os-brasileiros>. Acesso em: 15 set. 2017.

ZOCCOLI, Marilise Monteiro de Souza. Educação superior brasileira: política e legislação. Curitiba: Ibipex, 2009.

Recebido em: janeiro/2018

Aceito em: junho/2018

\section{Endereço para correspondência}

Larici Keli Rocha Moreira <larici.rocha@gmail.com>

Rod. Ernesto Alcyioli, Km 3 - Estrada do Forte

68377-630, Nova Colina, PA, Brasil 